\title{
Heating and ablation of tokamak graphite by pulsed nanosecond Nd-YAG lasers
}

\author{
A. Semerok, ${ }^{\text {a) }}$ S.V. Fomichev, ${ }^{\text {b) }}$ J.-M. Weulersse, F. Brygo, and P.-Y. Thro \\ CEA Saclay, DEN/DPC/SCP/LILM, Bât. 467, 91191 Gif sur Yvette, France \\ C. Grisolia \\ CEA Cadarache, DSM/DRFC, Bât. 506, 13108 Saint Paul Lez Durance, France
}

\begin{abstract}
The results on laser heating and ablation of graphite tiles of thermonuclear tokamaks are presented. Two pulsed Nd-YAG lasers $(20 \mathrm{~Hz}$ repetition rate, $5 \mathrm{~ns}$ pulse duration and $10 \mathrm{kHz}$ repetition rate, $100 \mathrm{~ns}$ pulse duration) were applied for ablation measurements. The ablation thresholds $\left(1.0 \pm 0.5 \mathrm{~J} / \mathrm{cm}^{2}\right.$ for $5 \mathrm{~ns}$ and $2.5 \pm 0.5 \mathrm{~J} / \mathrm{cm}^{2}$ for $100 \mathrm{~ns}$ laser pulses) were determined for the Tore Supra tokamak graphite tiles (backside) non-exposed to plasma. The high repetition rate Nd-YAG laser $(10 \mathrm{kHz}, 100 \mathrm{~ns}$ pulse duration) and the developed pyrometer system were applied for graphite heating measurements. Some unexpected features of laser heating of the graphite surface were observed. They were explained by the presence of a thin surface layer with the properties different from those of the bulk graphite. The theoretical models of laser heating and near-threshold ablation of graphite with imperfectly adhered layer were developed to interpret the experimental results.
\end{abstract}

PACS numbers: 28.52.Fa, 44.10.+i, 79.20.Ds, 81.05.Uw

\section{INTRODUCTION}

The excessive tritium trapping in deposited layers on tokamak plasma-facing components is seen as a severe problem for efficient operation of thermonuclear fusion reactors. ${ }^{1,2,3,4,5,6,7}$ To detritiate and clean plasmafacing surfaces of the future ITER, the completely optical methods of laser heating $8,9,10,11,12(\mathrm{LH})$ and laser ablation $^{13,14,15,16,17,18}$ (LA) can be suggested. Graphite surface detritiation by continuous wave $(\mathrm{CW})$ lasers in the heating regime with the temperatures up to $2300 \mathrm{~K}$ was reported in Ref. 9,10. LH was applied to release hydrogen isotopes from the deposited layer and to make hydrogen concentration measurements, ${ }^{19}$ rather than to remove the carbon deposit from the surface. For graphite, LA is observed when the surface temperature reaches the sublimation temperature $T_{\mathrm{S}} \approx 4200 \mathrm{~K} .^{20,21} \mathrm{CW}$ lasers may heat graphite surface up to this sublimation temperature only with the power of $1 \mathrm{~kW}$ or above (assuming $1 \mathrm{~mm}$ laser spot diameter). Powerful $(10-100 \mathrm{~W})$ pulsed Nd-YAG lasers of a high repetition rate are appropriate for decontamination of plasma-facing components in tokamaks by LA. ${ }^{22,23,24}$ Laser beam transport to the cleaning zone by an optical fiber allows to remove the laser system away from the contaminated zone and to perform a remote surface treatment. Personnel safety, reduced waste volume, laser beam accessibility to shadowed areas, and possible complete automation of the process are regarded as attractive advantages of laser decontamination.

To avoid graphite tiles damage during surface detritiation, LA thresholds for graphite and deposited layer

\footnotetext{
a) E-mail: alexandre.semerok@cea.fr

b) On leave from RRC "Kurchatov Institute", Kurchatov pl., 123182 Moscow, Russia
}

should be determined. The ablation threshold and rate of a carbon deposit depend on the deposited layer properties (thickness, density, thermal and optical parameters). To our knowledge, these properties are not sufficiently known. They may differ significantly from the corresponding properties of tokamak graphite, which are also not well known. ${ }^{20,21,25,26,27,28}$ To obtain the layer and/or substrate properties, it is necessary to measure the thermal response of the surface to the transient heat pulse. $^{29}$

To study laser detritiation of tokamak graphite tiles, two experimental laser benches were developed in our laboratory (CEA Saclay, France). The first experimental set-up based on a commercial Q-Switched Nd-YAG laser ("Brilliant" QUANTEL) was designed to study LA with short $(4-10 \mathrm{~ns}$ FWHM) laser pulses of a low repetition rate $(20 \mathrm{~Hz}$ or single pulses $)$. The second set-up was based on a Q-Switched high repetition rate Nd-YAG laser developed in CEA Saclay. It was applied for LA and LH experiments with longer $(\approx 100 \mathrm{~ns}$ FWHM) pulses of a laser repetition rate $\left(\nu_{\mathrm{L}}\right)$ up to $10 \mathrm{kHz}$. Laser radiation at the wavelength $\left(\lambda_{\mathrm{L}}\right)$ of $532 \mathrm{~nm}$ provided up to $180 \mathrm{~mJ}$ pulse energy with $5 \mathrm{~ns}$ pulses at low $\nu_{\mathrm{L}}=20 \mathrm{~Hz}$ and up to $100 \mathrm{~W}$ mean power with $100 \mathrm{~ns}$ pulses at high $\nu_{\mathrm{L}}=10 \mathrm{kHz}$. The $5 \mathrm{~ns}$ Gaussian laser beam was homogenized by a diaphragm with imaging the central zone of the beam onto the surface. The $100 \mathrm{~ns}$ laser beam was transported to the interaction zone by a multimode optical silica fiber of $15 \mathrm{~m}$ length, $1 \mathrm{~mm}$ core diameter, and 0.2 numerical aperture. Laser beam intensity distribution was homogeneous at the fiber exit. Thus, the homogenized laser beams of $0.6-3 \mathrm{~mm}$ spot size (depending on focusing) on the irradiated surface were used in the experiments with two benches. Different fluences for 5 ns laser were obtained by varying the laser pulse energy, but keeping the fixed laser spot diameter $(1 \mathrm{~mm})$. For 100 ns laser pulses, different laser fluences at the constant laser pulse energy $(6 \mathrm{~mJ})$ were obtained by varying 
the laser spot diameter.

Theoretical models of LH and near-threshold LA of complex surfaces with a layer by periodically repeating nanosecond laser pulses were developed. The models may describe LH and LA both with the temperature-dependent matter parameters and their mean temperature-independent values. The threedimensional (3D) analytical LH model ${ }^{30,31}$ provides calculations of the heating temperature for any number of applied laser pulses. The one-dimensional (1D) numerical model of LA of sublimating materials (graphite) allows to calculate LA depth with consideration of the temperature dependences (if known) of the surface properties. The intermediate adhesion between the layer and the substrate was applied in both models. The comparative experimental and theoretical studies on LH and LA of graphite samples allowed to characterize a deposited carbon layer and to determine some poorly known properties of tokamak graphite.

The paper presents the results on near-threshold LA and LH of tokamak graphite (backside non-plasma-facing surfaces of Tore Supra tokamak tiles) by pulsed nanosecond Nd-YAG lasers. Section II analyzes the experimental and simulation results on LA of graphite tiles. Laser absorption coefficient of graphite at $\lambda_{\mathrm{L}}=532 \mathrm{~nm}$ is estimated with the help of the LA thresholds determined for two pulse durations ( $5 \mathrm{~ns}$ and $100 \mathrm{~ns}$ ). Section III presents the results on LH of graphite by high repetition rate pulses. The LH properties of the original surface of manufactured graphite tiles were significantly different from those of the same surface, but pre-processed by LA. The presence of a thin boundary graphite layer is suggested to explain the observed difference in the LH properties. Section IV makes the conclusions. The simulation models for LH and LA are outlined in Appendices A and $\mathrm{B}$, respectively. The discussion on plasma-facing surface of graphite tiles with a deposited carbon layer is beyond the scope of this paper.

\section{LASER ABLATION OF TOKAMAK GRAPHITE}

\section{A. Experimental results}

LA of a non-plasma-facing (backside) surface of Tore Supra graphite was performed with short pulses of $\tau_{\mathrm{p}}=$ 5 ns at a low $\nu_{\mathrm{L}}=20 \mathrm{~Hz}$. The LA threshold $F_{\text {th }}$ for Tore Supra graphite was $1.0 \pm 0.5 \mathrm{~J} / \mathrm{cm}^{2}$. The crater depth $H$ (per laser pulse) may be approximated by a linear function of laser fluence $F$ up to $5 \mathrm{~J} / \mathrm{cm}^{2}$ (Fig. 1):

$$
H \approx \beta\left(F-F_{\mathrm{th}}\right),
$$

with the coefficient $\beta \approx 0.033 \mu \mathrm{m} \cdot \mathrm{cm}^{2} / \mathrm{J}$. The linear dependence was disturbed at the laser fluence above $5 \mathrm{~J} / \mathrm{cm}^{2}$. The linearity upset may be explained by the high laser pulse intensity $\left(\sim 1 \mathrm{GW} / \mathrm{cm}^{2}\right)$ which may cause plasma formation during LA. Plasma screening

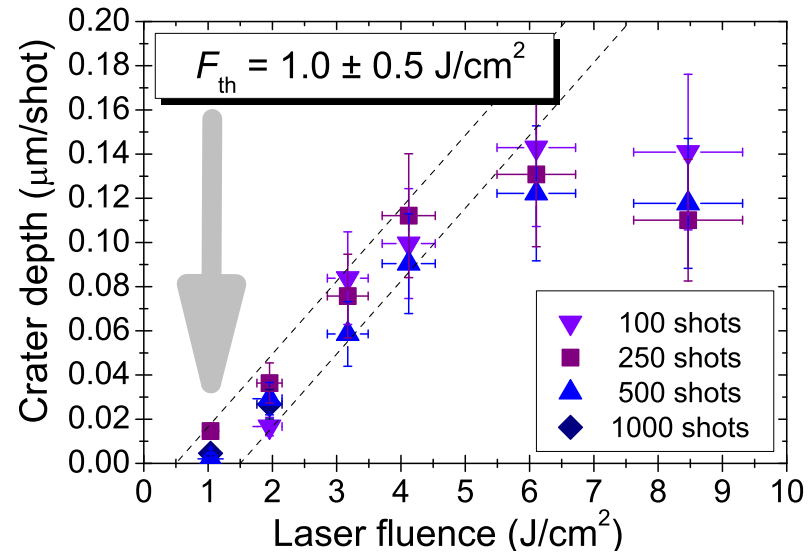

FIG. 1: (Color online) Crater depth (normalized to one laser shot) as a function of laser fluence for a number of laser shots applied for crater formation. Tore Supra graphite, nonplasma-facing surface, $\lambda_{\mathrm{L}}=532 \mathrm{~nm}, \tau_{\mathrm{p}}=5 \mathrm{~ns}, \nu_{\mathrm{L}}=20 \mathrm{~Hz}$. Laser spot diameter is $1 \mathrm{~mm}$.

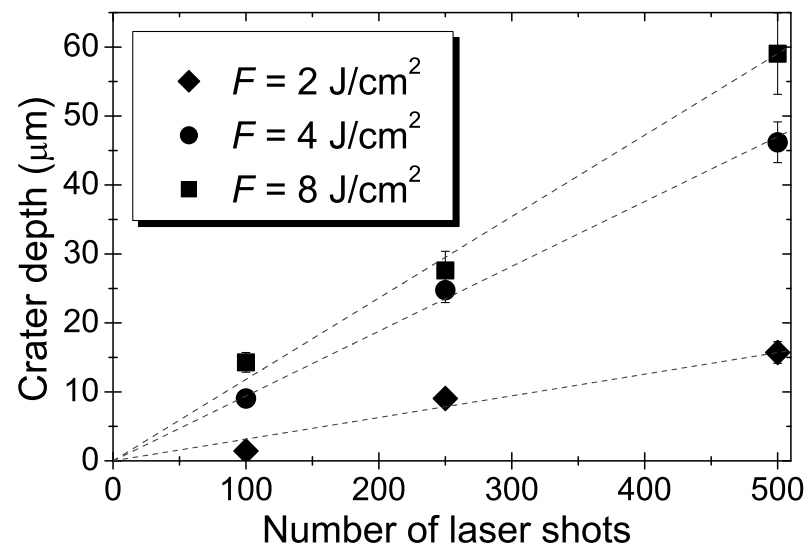

FIG. 2: Crater depth as a function of a number of applied laser shots for different laser fluences $F$. Tore Supra graphite, non-plasma-facing surface, $\lambda_{\mathrm{L}}=532 \mathrm{~nm}, \tau_{\mathrm{p}}=5 \mathrm{~ns}, \nu_{\mathrm{L}}=$ $20 \mathrm{~Hz}$. Laser spot diameter is $1 \mathrm{~mm}$.

may reduce LA rate and, thus, results in saturation of the crater depth dependence versus the laser fluence. The crater depth (Fig. 2) was a linear function of the number of applied laser pulses (up to 500 shots) when the resulting crater depth was much lower than the crater diameter.

For a low repetition rate heating $(20 \mathrm{~Hz})$, thermal energy accumulation by the graphite surface from pulse to pulse was negligible. With each laser pulse, the surface LH re-commenced from the same ambient temperature $T_{0}$ (room temperature). The important thermal energy accumulation from pulse to pulse was expected for the high $(10 \mathrm{kHz})$ repetition rate heating. As a result, LA rates were expected to be significantly different for low and high repetition rate pulses of the same du- 


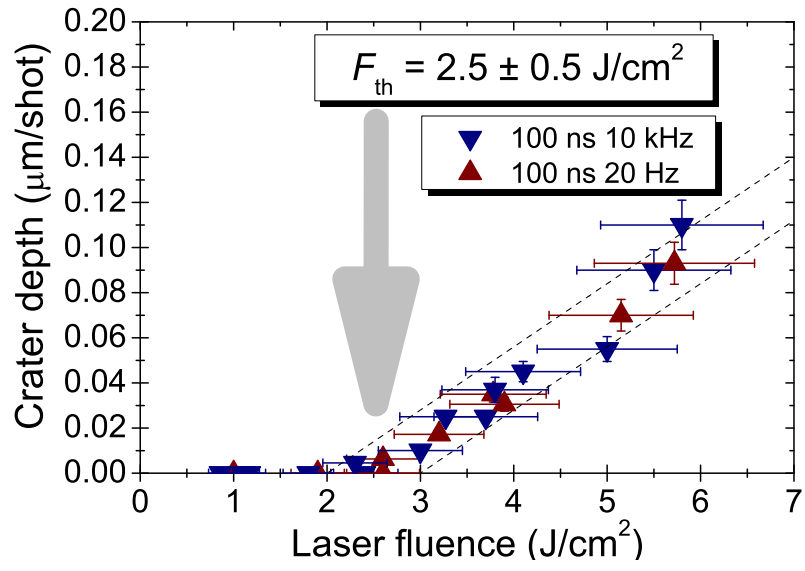

FIG. 3: (Color online) Crater depth (normalized to one laser shot) as a function of laser fluence. Tore Supra graphite, nonplasma-facing surface, $\lambda_{\mathrm{L}}=532 \mathrm{~nm}, \tau_{\mathrm{p}}=100 \mathrm{~ns}, \nu_{\mathrm{L}}=10 \mathrm{kHz}$ $(\boldsymbol{\nabla})$ and $20 \mathrm{~Hz}(\boldsymbol{\Lambda}), 100$ or 1000 laser shots per crater. Laser pulse energy is $6 \mathrm{~mJ}$.

ration. However, the experimental results obtained with the backside surface of Tore Supra graphite samples did not support these estimations. For $100 \mathrm{~ns}$ laser pulses, no important difference in LA rates for $\nu_{\mathrm{L}}$ of $20 \mathrm{~Hz}$ and $10 \mathrm{kHz}$ was observed within the measurements accuracy (Fig. 3). 100 or 1000 pulses were applied to form the craters. For this number of pulses, the accumulated heat was expected close to maximum.

For 100 ns laser pulses, the linear dependences of the crater depth from the laser fluence and the number of applied laser pulses were observed for low and high repetition rates. The crater depth dependence on laser fluence can be approximated by a linear function (Eq. 1) with $\beta \approx 0.028 \mu \mathrm{m} \cdot \mathrm{cm}^{2} / \mathrm{J}$ (Fig. 3). The LA threshold $F_{\text {th }}$ was $2.5 \pm 0.5 \mathrm{~J} / \mathrm{cm}^{2}$ for both repetition rates. This threshold was 2.5 times higher than the one of $\approx 1 \mathrm{~J} / \mathrm{cm}^{2}$ for $5 \mathrm{~ns}$ laser pulses. The difference in the LA thresholds can be associated with the pulse durations. Amorphous reactor graphite can be referred to the matter with metal-like properties. ${ }^{20,21,25,26,27,28}$ For these samples, the ratio of LA thresholds should be close to the square root from the ratio of the corresponding nanosecond pulse durations, ${ }^{32}$ that is, approximately 4.5 for our experiments. For Tore Supra graphite, the experimentally obtained threshold ratio of 2.5 can be associated with the sufficiently low laser absorption coefficient (at $\lambda_{\mathrm{L}}=532 \mathrm{~nm}$ ) in the temperature range between the ambient $T_{0}$ and sublimation $T_{\mathrm{S}}$ temperatures.

\section{B. Simulations of laser ablation}

To simulate LH/LA of a graphite surface, one should know thermal and optical properties of tokamak graphite in the temperature range above the ambient temperature $T_{0} \approx 300 \mathrm{~K}$ and below the graphite sublimation tem-
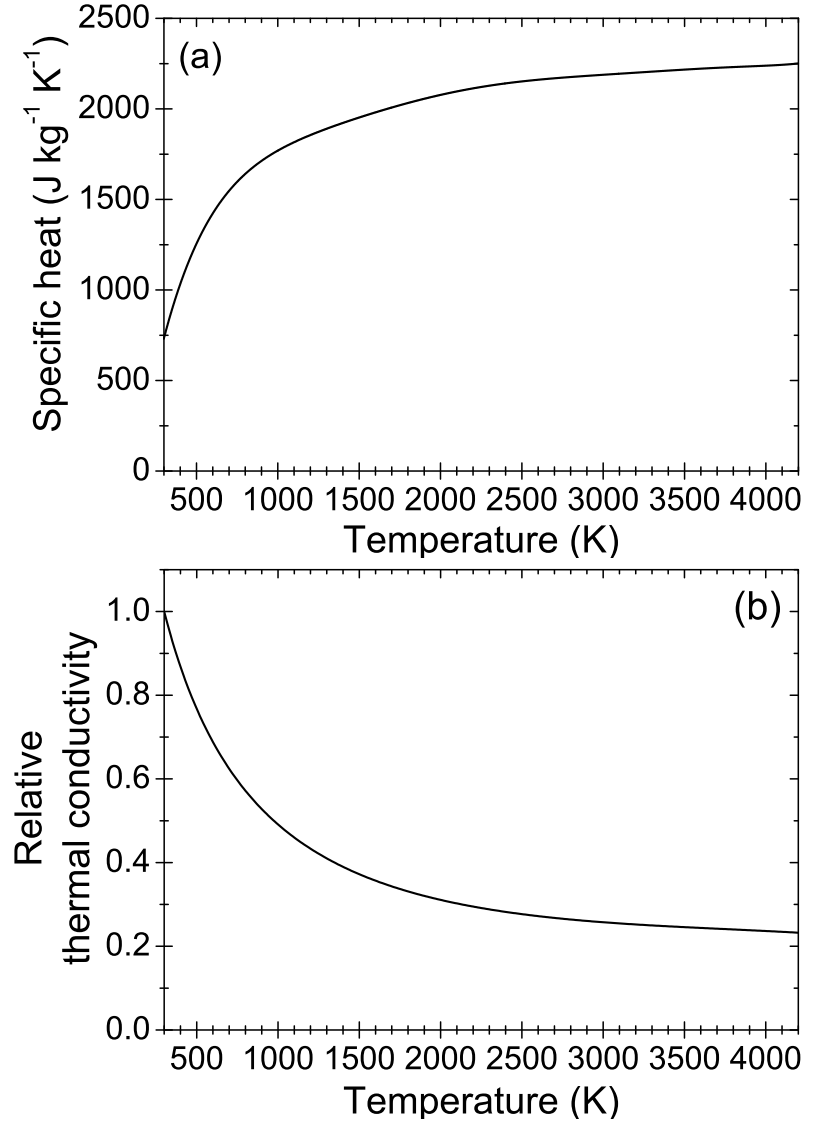

FIG. 4: Graphite thermal properties: (a) mass specific heat and (b) relative thermal conductivity (with respect to thermal conductivity at $T_{0}=300 \mathrm{~K}$ ).

perature $T_{\mathrm{S}} \approx 4200 \mathrm{~K}$. The graphite tiles density of $\rho_{\mathrm{G}} \approx 1700 \mathrm{~kg} / \mathrm{m}^{3}$ is typical for manufactured graphite in nuclear industry. ${ }^{20}$ The natural graphite density is $\rho_{0} \approx 2240 \mathrm{~kg} / \mathrm{m}^{3} \cdot{ }^{20,21}$ Thus, for tokamak graphite tiles, the mean porosity $p_{\mathrm{G}} \approx 25 \% .^{20}$

Mass specific heat of graphite (Fig. 4a) is a temperature dependent parameter. ${ }^{20,21,33}$ The mean mass specific heat is $c_{0} \approx 1500 \mathrm{~J} /(\mathrm{kg} \cdot \mathrm{K})$. Knowing the graphite tile porosity, the mean volume specific heat of Tore Supra graphite is estimated as $c_{\mathrm{G}}=\left(1-p_{\mathrm{G}}\right) \rho_{0} c_{0} \approx$ $2.5 \mathrm{MJ} /\left(\mathrm{m}^{3} \cdot \mathrm{K}\right)$. The graphite thermal conductivity $k\left(T_{0}\right)$ at room temperature should be considered as an adjusting parameter due to the scatter in the data on this parameter. ${ }^{20,21,25,26,27,28}$ The temperature dependent relative thermal conductivity $k(T) / k\left(T_{0}\right)$ is available from Ref. 20 (Fig. 4b). Thermal conductivity $k\left(T_{0}\right)$ of mono-crystal natural graphite at room temperature may vary in $2-2000 \mathrm{~W} /(\mathrm{m} \cdot \mathrm{K})$ range for different directions to crystal axes. ${ }^{21}$ For amorphous Tore Supra tokamak graphite, $k\left(T_{0}\right)=120 \mathrm{~W} /(\mathrm{m} \cdot \mathrm{K})$ was obtained by fitting the LH and LA experimental results with the calculations. The obtained value is in a good agreement with the thermal conductivity of Tore Supra graphite ${ }^{26}$ 
(CEA Cadarache, France), with the data in Ref. 14, and close to the thermal conductivity of some metals. ${ }^{21}$ Thus, the mean thermal conductivity of tokamak graphite in $300-4200 \mathrm{~K}$ temperature range is $k_{\mathrm{G}} \approx 60 \mathrm{~W} /(\mathrm{m} \cdot \mathrm{K})$ (Fig. 4b).

Graphite can be referred to semi-metals ${ }^{34}$ with the noticeable dependence of the laser absorption coefficient on temperature. To our knowledge, the temperature dependences of graphite optical properties are not available in literature. At $\lambda_{\mathrm{L}}=532 \mathrm{~nm}$, laser absorption coefficient and reflectivity of natural dense graphite at room temperatures can be obtained from the experimental data of Ref. 27. The determined absorption coefficient is $\alpha_{0}\left(T_{0}\right) \approx 34 \mu \mathrm{m}^{-1}$. For porous tokamak graphite, the absorption coefficient can be estimated as $\alpha\left(T_{0}\right)=\left(1-p_{\mathrm{G}}\right) \alpha_{0}\left(T_{0}\right) \approx 25 \mu \mathrm{m}^{-1}$. These values are close to the typical metal absorption coefficients. The reflectivity of natural dense graphite at room temperature is estimated as $R_{0} \approx 0.29$. The reflectivity $R_{\mathrm{G}}$ of the tokamak graphite is low due to porosity. The linear approximation on graphite density for both the refractive index and the absorption coefficient can be applied. Thus, $R_{\mathrm{G}} \approx 0.22$. Graphite reflectivity does not strongly depend on temperature, as it is mainly determined by polarizability of ion cores, rather than free electrons. ${ }^{34}$

Heating depth is proportional to $\left(D_{\mathrm{G}} \tau_{\mathrm{p}}\right)^{1 / 2}$, where $D_{\mathrm{G}}=k_{\mathrm{G}} / c_{\mathrm{G}} \approx 0.24 \mathrm{~cm}^{2} / \mathrm{s}$ is the mean thermal diffusivity of graphite, and $\tau_{\mathrm{p}}$ is pulse duration. For the same laser fluence, the longer the laser pulse duration is, the deeper the heat penetration and the lower the heating temperature. Thus, LA threshold $F_{\text {th }}$ should depend on the laser pulse duration as $\tau_{\mathrm{p}}^{1 / 2}$, if the heating depth is much higher than the laser absorption length. This threshold dependence is well known for the metal heating by nanosecond laser pulses ${ }^{32}$ with the surface heating temperature $\Delta T \equiv T-T_{0}=\{2(1-$ $\left.\left.\left.R_{\mathrm{G}}\right) /\left(\pi c_{\mathrm{G}} k_{\mathrm{G}}\right)^{1 / 2}\right)\right\} F / \tau_{\mathrm{p}}^{1 / 2}$ reached by the end of laser heating pulses (for the rectangular pulse heating model). This is the case of "surface heating regime" (in contrast to "volume heating regime" where $\Delta T$ does not depend on $\left.\tau_{\mathrm{p}}{ }^{32,35,36}\right)$. For surface heating regime, the additional condition $\left(D_{\mathrm{G}} \tau_{\mathrm{p}}\right)^{1 / 2} \ll r_{0}$ should be satisfied $\left(r_{0}\right.$ is the radius of the laser spot on the surface). This condition was always met in our LA experiments with $r_{0} \sim 500 \mu \mathrm{m}$.

From the available data on natural graphite, the absorption length at $\lambda_{\mathrm{L}}=532 \mathrm{~nm}$ at room temperature is less than $0.1 \mu \mathrm{m}$. The heat penetration depth is $\sim 1 \mu \mathrm{m}$ for laser pulses applied in our experiments. Thus, for $100 \mathrm{~ns}$ and $5 \mathrm{~ns}$ pulses, the LA thresholds ratio should be close to $(100 / 5)^{1 / 2} \approx 4.5$. This would be true, if the absorption length of laser radiation were much lower than the thermal diffusion length for both pulse durations. The low thresholds ratio of 2.5 obtained in the experiments with Tore Supra graphite can be associated with the increase in the laser absorption length with the temperature increase up to $T_{\mathrm{S}}$. In this case, the strong inequality $\alpha_{\mathrm{G}}^{-1} \ll\left(D_{\mathrm{G}} \tau_{\mathrm{p}}\right)^{1 / 2}$ is violated (mostly for $5 \mathrm{~ns}$ pulses). Thus, the square root dependence for

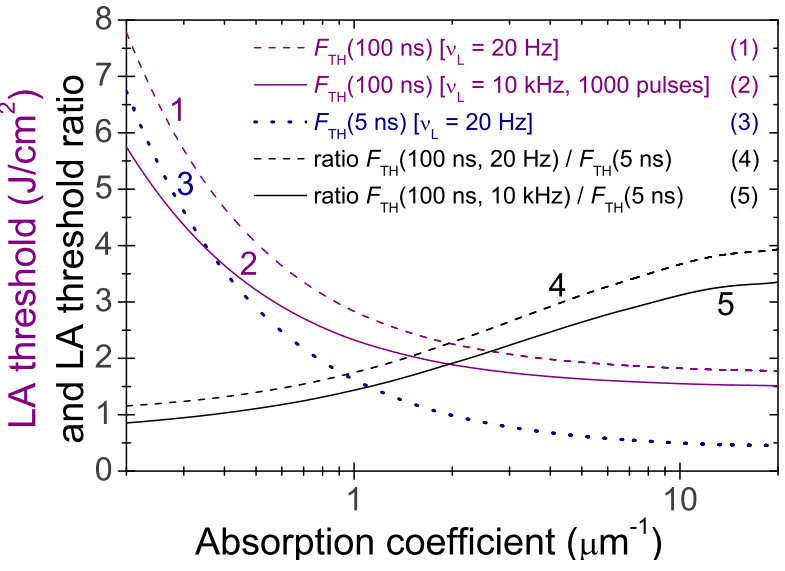

FIG. 5: (Color online) Calculated LA thresholds of tokamak graphite for $5 \mathrm{~ns}(20 \mathrm{~Hz}$ repetition rate) and $100 \mathrm{~ns}$ laser pulses $(20 \mathrm{~Hz}$ and $10 \mathrm{KHz}$ repetition rate) and ratio of LA thresholds as a function of the mean absorption coefficient of the graphite.

surface temperature, that is valid only for "surface heating regime", can not be applied. For the other limiting case with $\alpha_{\mathrm{G}}^{-1} \gg\left(D_{\mathrm{G}} \tau_{\mathrm{p}}\right)^{1 / 2}$ ("volume heating regime"), the surface temperature does not depend on the pulse duration, and the LA thresholds would be the same for both $5 \mathrm{~ns}$ and $100 \mathrm{~ns}$ laser pulses.

The dependences of LA thresholds and their ratios versus $\alpha_{\mathrm{G}}$ (Fig. 5) were calculated by the developed 3D LH model (Appendix A) with mean constant graphite parameters. The LA thresholds were determined for rectangular laser pulses that heated the graphite surface up to the sublimation temperature $T_{\mathrm{S}}$. For $100 \mathrm{~ns}$ laser pulses, the laser beam was of $6 \mathrm{~mJ}$ pulse energy. Laser fluence was adjusted by varying the laser spot diameter. For $5 \mathrm{~ns}$ pulses, with the fixed radius $r_{0}=500 \mu \mathrm{m}$, laser fluence was adjusted by the pulse energy. For $\tau_{\mathrm{p}}=100 \mathrm{~ns}$ (for both $\nu_{\mathrm{L}}$ of $20 \mathrm{~Hz}$ and $10 \mathrm{kHz}$ ) and $\tau_{\mathrm{p}}=5 \mathrm{~ns}\left(\right.$ for $\left.\nu_{\mathrm{L}}=20 \mathrm{~Hz}\right)$, the experimentally obtained ablation thresholds and their ratios can be explained theoretically only if we accept the sufficiently low mean absorption coefficient $\alpha_{\mathrm{G}}=2 \mu \mathrm{m}^{-1}$ of tokamak graphite at $\lambda_{\mathrm{L}}=532 \mathrm{~nm}$. This value is used in our calculations, as it gives the best fit for the experimental results. For dense graphite (with zero porosity), the mean laser absorption coefficient is $\alpha_{0} \approx \alpha_{\mathrm{G}} /\left(1-p_{\mathrm{G}}\right) \approx 2.67 \mu \mathrm{m}^{-1}$.

The difference in the theoretical LA thresholds for graphite at $\tau_{\mathrm{p}}=100 \mathrm{~ns}$ for high $(10 \mathrm{kHz})$ and low $(20 \mathrm{~Hz})$ repetition rates (Fig. 5) may be associated with thermal energy accumulation by the surface from pulse to pulse at $10 \mathrm{kHz}$ repetition rate. For a high repetition rate, the surface cooling between two subsequent pulses is not complete. The residual heating temperature is permanently increasing with the number of applied pulses until it reaches the stable value $\Delta T^{\star}$. Based on the heat equation solution, ${ }^{35,36}$ the time $t^{\star}$ required to reach the temperature $\Delta T^{\star}$ is estimated from $\left(D_{\mathrm{G}} t^{\star}\right)^{1 / 2} \sim r_{0} . \Delta T^{\star}$ can be 


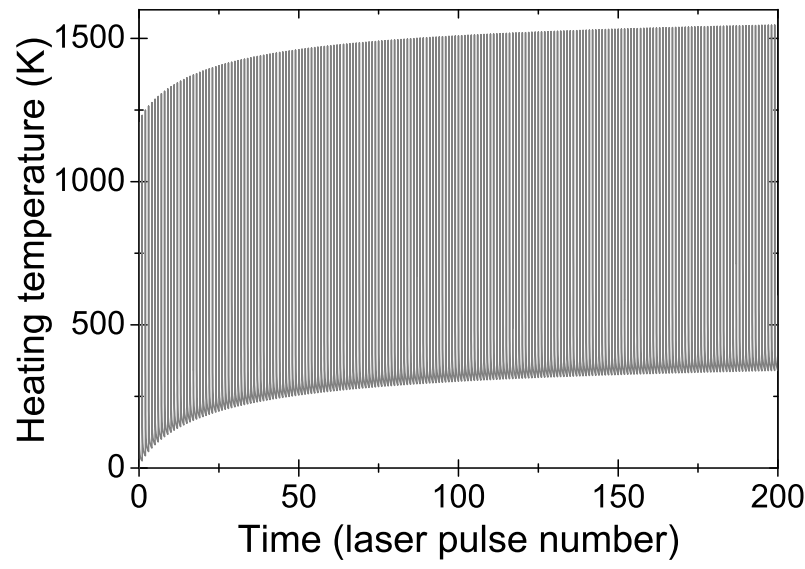

FIG. 6: Calculated profile of the surface heating temperature $\Delta T=T-T_{0}$ of the tokamak graphite (with the above parameters) at heating by 200 laser pulses of $10 \mathrm{kHz}$ repetition rate and $100 \mathrm{~ns}$ pulse duration. $T_{0}$ is ambient temperature. Laser fluence $F=0.7 \mathrm{~J} / \mathrm{cm}^{2}$.

estimated from $\Delta T^{\star} \approx 0.5 F\left(1-R_{\mathrm{G}}\right) r_{0} \nu_{\mathrm{L}} \pi^{1 / 2} / k_{\mathrm{G}}$. This expression corresponds to $\mathrm{CW}$ LH with the power equal to the average one of the pulsed laser with the repetition rate $\nu_{\mathrm{L}}$. For the heating time $t \gg t^{\star}, \mathrm{LH}$ starts from the surface temperature $T_{0}+\Delta T^{\star}$. For tokamak graphite with the above thermal parameters and $r_{0} \approx 522 \mu \mathrm{m}, t^{\star}$ corresponds to $\approx 100$ laser pulses, and the pre-heating temperature $\Delta T^{\star} \approx 420 \mathrm{~K}$ for $F=0.7 \mathrm{~J} / \mathrm{cm}^{2}$ and $\nu_{\mathrm{L}}=10 \mathrm{kHz}$ is reached with a few hundred laser pulses.

The 3D analytical model of LH (Appendix A) was applied to calculate the temperature profile for 200 laser pulses (Fig. 6). For a high repetition rate $(10 \mathrm{kHz})$ and a sufficient number of applied laser pulses, the pre-heating effect reduced the LA threshold. For a low repetition rate $\left(\nu_{\mathrm{L}}=20 \mathrm{~Hz}\right)$, the pre-heating is negligible. The LA rates of tokamak graphite were calculated with the developed Stefan-like model for LA of sublimating/evaporating materials (Appendix B). The model is based on the numerical solution of the $1 \mathrm{D}$ heat equation with the Stefan boundary condition. ${ }^{32,37}$ The 1D approach (on a single-shot time scale) is relevant for our experimental conditions. The pre-heating effect may be important for a high repetition rate and a high number of laser shots applied for crater formation. It was incorporated in the LA model phenomenologically. The temperature dependences of specific heat and thermal conductivity of graphite (Fig. 4) were taken into account in the LA model. Other parameters were taken as mean constant values. Mass specific heat of sublimation was taken as $50 \mathrm{MJ} / \mathrm{kg}$ from Ref. 20. Figure 7 presents LA rates for the temporal shape of the laser pulse of $\sin ^{2}\left(\pi t / 2 \tau_{\mathrm{p}}\right)$ $\left(0 \leq t \leq 2 \tau_{\mathrm{p}}\right)$. The calculated crater depth dependences on laser fluence near the LA thresholds are not linear. This may explain the fact that the theoretical LA threshold is slightly lower than the one defined by the linear fit of the experimental ablation depths. A good

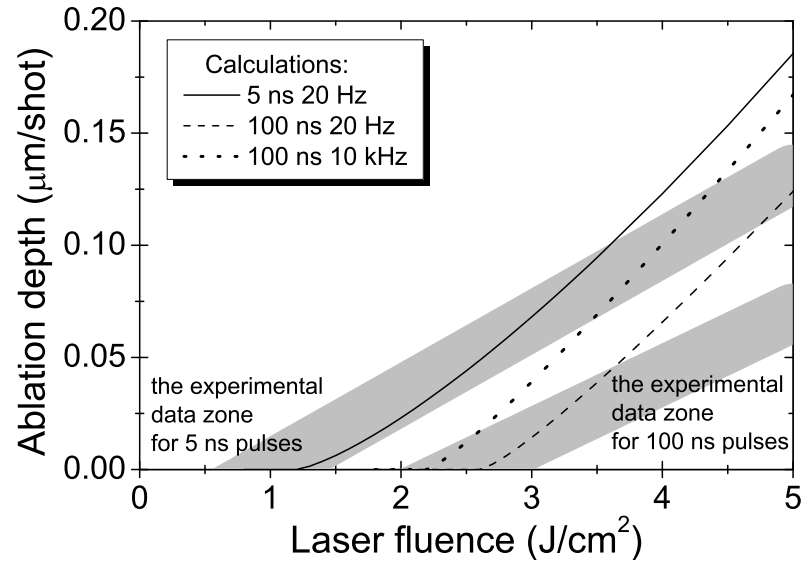

FIG. 7: Calculated and experimental ablation rates of Tore Supra graphite sample versus laser fluence (see Fig. 1 for experimental results for $5 \mathrm{~ns}$ pulses at $20 \mathrm{~Hz}$ repetition rate and Fig. 3 for $100 \mathrm{~ns}$ pulses at $20 \mathrm{~Hz}$ and $10 \mathrm{kHz}$ repetition rates).

agreement between the calculated and experimental LA rates was obtained for $5 \mathrm{~ns}$ laser pulses $\left(\nu_{\mathrm{L}}=20 \mathrm{~Hz}\right)$ for laser fluences below $3.5 \mathrm{~J} / \mathrm{cm}^{2}$. For higher laser fluences, the experimental LA rates are lower than the theoretical ones. It may be associated with the plasma screening of $5 \mathrm{~ns}$ laser beam. The screening effect was not considered in the LA model, which was developed for threshold determination.

For 100 ns laser pulses, the calculation and experimental results are in agreement only near the LA threshold. For higher laser fluences, the difference between the calculation and experimental results may be associated with the laser beam screening (diffusion) by the ablation products (micro particles). At different repetition rates $(20 \mathrm{~Hz}$ and $10 \mathrm{kHz})$, the pronounced difference between the theoretical LA rates (Fig. 7) may be attributed to the different intensity of heat accumulation. Within the measurement accuracy, this difference was not observed experimentally.

The quantitative agreement between the theoretical and experimental results near ablation thresholds for both pulse durations has validated the applicability of the developed LA model to tokamak graphite with the thermal and optical parameters specified above.

\section{HIGH REPETITION RATE LASER HEATING OF TORE SUPRA GRAPHITE}

\section{A. Experimental results}

The experimental pyrometer system based on an Impac-Kleiber C-LWL infra-red pyrometer was developed in our laboratory to study high repetition rate LH. The pyrometer system parameters were as follows: $600-2600 \mathrm{~K}$ temperature range, $1.6-2.2 \mu \mathrm{m}$ working 

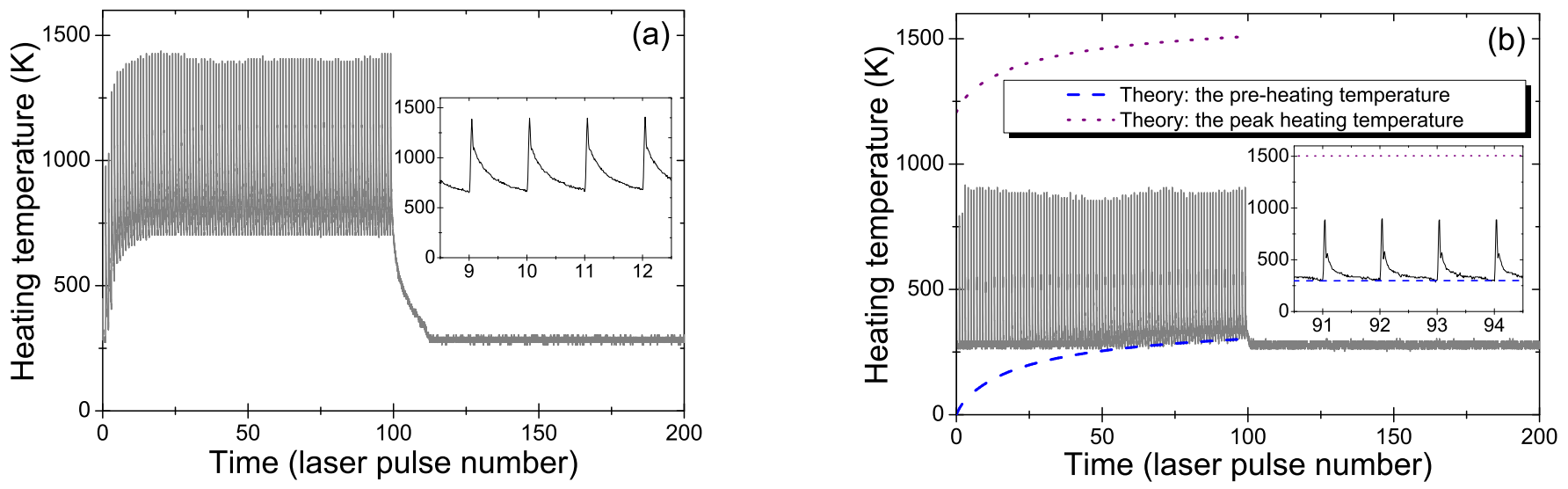

FIG. 8: (Color online) Panel (a) - experimental results on high repetition rate $(10 \mathrm{kHz}) \mathrm{LH}$ of the non-plasma-facing surface of Tore Supra graphite by 100 laser pulses at laser fluence $F=0.62 \mathrm{~J} / \mathrm{cm}^{2}$. Panel (b) - LH measurements at laser fluence $F=0.7 \mathrm{~J} / \mathrm{cm}^{2}$ for the same surface, but pre-processed by LA. Theoretical data for pre-heating and peak heating temperatures (see Fig. 6) are presented by the dash and dot curves, respectively. The surface heating temperature is $\Delta T=T-T_{0}, T_{0}$ is ambient temperature.

wavelength range, $15 \mu$ s response time $\left(t_{99 \%}\right)$.

The simulation results on LH of graphite surface by $100 \mathrm{~ns}$ laser pulses at $\nu_{\mathrm{L}}=10 \mathrm{kHz}$ and $0.7 \mathrm{~J} / \mathrm{cm}^{2}$ laser fluence (Fig. 6) were taken as the reference point in the pyrometer measurements of tokamak graphite temperature. The measured temperature was expected close to the one of Fig. 6. But the experimental temperatures were quite different (Fig. 8a). For $0.62 \mathrm{~J} / \mathrm{cm}^{2}$ laser fluence, the preheating temperatures were higher than expected. The time $t^{\star}$ required to reach the pre-heating temperature saturation $\Delta T^{\star}$ was ten times less than the theoretical one estimated from the specified tokamak graphite parameters and was corresponding to ten laser pulses. The pre-heating temperatures were extraordinarily stable from approximately the $15^{\text {th }}$ laser pulse. A number of LH simulations were made to obtain the experimental temperature profile (Fig. 8a). Nevertheless, the simulation efforts were not successful, even with the significantly modified graphite parameters.

A hypothesis on a thin (micrometer) boundary layer on the graphite surface with the properties different from those of the bulk graphite was suggested to explain the experimental results. During the initial LH by the first ten laser pulses, the surface temperature increases significantly due to the reduced thermal conductivity of the layer. When the heating depth becomes higher than the layer thickness, the bulk graphite properties are the main factors, which slow down the pre-heating temperature increase. The preliminary results on the modelling with this hypothesis in mind are presented in Ref. 30,31. The physical nature of this layer is not yet clear. As the graphite was not exposed to plasma, the layer formation might be due to mechanical cutting in manufacturing tokamak graphite tiles.

To check the boundary layer hypothesis, LH was performed on a surface area, which was pre-processed by
LA. A thin layer of $4 \pm 2 \mu \mathrm{m}$ depth was removed from the surface by LA. The pyrometer temperature trace from the pre-processed area (Fig. 8b) did not reproduce the temperature profile of Fig. 8a, but was similar to the theoretical one for the bulk graphite (Fig. 6). The comparison of the theoretical and experimental results was not able to confirm the LH trace of the pre-processed graphite surface (Fig. 8b) due to a long $15 \mu$ s response time of the pyrometer, that is, 150 times longer than $100 \mathrm{~ns}$ laser pulse duration. Thus, the actual peak heating temperature reached on the pulse duration scale can not be measured by the pyrometer, and it should be higher than the experimental peak temperature. As the low temperature limit of the pyrometer is about $600 \mathrm{~K}$, it is not possible to measure the whole temperature profile for the pre-processed surface. For LH by 100 laser pulses at $0.7 \mathrm{~J} / \mathrm{cm}^{2}$ fluence, the pre-heating temperatures are slightly above $600 \mathrm{~K}$ only from the $60^{\text {th }}$ laser pulse. The pre-heating temperature depends on the adjusting parameter of thermal conductivity coefficient, rather than on laser absorption coefficient. The latter affects only the peak heating temperature. From the comparison of the pyrometer measurements with the theoretical data, the mean thermal conductivity for tokamak bulk graphite was determined as $60 \mathrm{~W} /(\mathrm{m} \cdot \mathrm{K})$.

\section{B. Simulations of graphite laser heating and characterization of surface layer}

The extraordinary stability of the experimental preheating temperature from the $15^{\text {th }}$ laser pulse (Fig. 8a) may be associated with LA of a thin layer on the surface even at $0.62 \mathrm{~J} / \mathrm{cm}^{2}$ laser fluence. During LA, the peak surface temperature should be the same as the graphite sublimation temperature $T_{\mathrm{S}}$. After each laser pulse ap- 

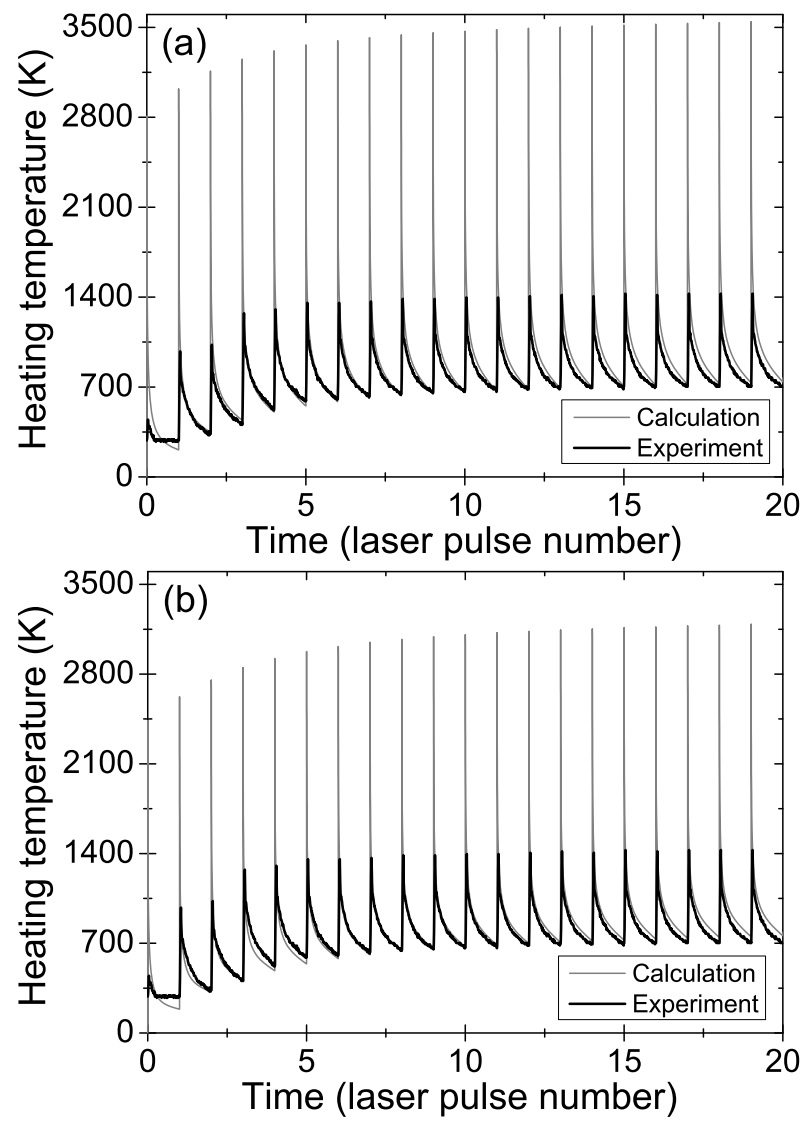

FIG. 9: Calculated high repetition rate $(10 \mathrm{kHz}) \mathrm{LH}$ of graphite surface with the layer (with the properties different from those of bulk graphite) and experimental results from Fig. 8a for the first twenty laser pulses. Panel (a) - calculated results for $p_{\mathrm{L}}=25 \%, d=8 \mu \mathrm{m}, k_{\mathrm{L}}=0.75 \mathrm{~W} /(\mathrm{m} \cdot \mathrm{K})$, and $h=140 \mathrm{~kW} /\left(\mathrm{m}^{2} \cdot \mathrm{K}\right)$. Panel (b) - calculated results for $p_{\mathrm{L}}=$ $0, d=6 \mu \mathrm{m}, k_{\mathrm{L}}=0.75 \mathrm{~W} /(\mathrm{m} \cdot \mathrm{K})$, and $h=90 \mathrm{~kW} /\left(\mathrm{m}^{2} \cdot \mathrm{K}\right)$. Laser fluence $F=0.62 \mathrm{~J} / \mathrm{cm}^{2}$. The surface heating temperature is $\Delta T=T-T_{0}, T_{0}$ is ambient temperature.

plication, the surface cooling starts from this $T_{\mathrm{S}}$. The minimal temperature by the end of cooling (before next pulse application) should be the same for all repetitive laser pulses. Thus, the significant stability of the preheating temperature might be explained by LA.

The upper working temperature limit of the pyrometer is $2600 \mathrm{~K}$. If the surface temperature is above, the correct pyrometer measurements may be disturbed by the pyrometer photocurrent saturation. Thus, only the initial non-saturated part of the LH trace may be referred to compare the experimental and simulation results.

The initial part of the LH trace (before pre-heating temperature stabilization) can be fitted with three adjusting parameters. The pre-heating temperature profile (magnitude and curvature) can be adjusted by two parameters. The third parameter can be used to adjust the cooling curve between two consecutive laser pulses. For a given layer porosity $p_{\mathrm{L}}$, three adjusting parameters are the layer thickness $d$, the layer thermal conductivity $k_{\mathrm{L}}$, and the heat transfer coefficient $h$ (layer adhesion quality) on the interface between the layer and the bulk graphite (Eq. (A4), Appendix A). The layer heat capacity and the coefficients of layer light absorption and reflection can be obtained from $p_{\mathrm{L}}$ and bulk graphite parameters. Figure $9 \mathrm{a}$ presents the fit for $p_{\mathrm{L}}=25 \%$. The best fit was obtained with $d=8 \mu \mathrm{m}, k_{\mathrm{L}}=0.75 \mathrm{~W} /(\mathrm{m} \cdot \mathrm{K})$, and $h=140 \mathrm{~kW} /\left(\mathrm{m}^{2} \cdot \mathrm{K}\right)$.

The heating temperature of a thin layer is determined by the layer heat capacity (per unit of surface) that is proportional to the product of the layer thickness and the layer specific heat, which, in turn, is proportional to the layer density. Thus, the layer heating temperature depends on the product $d\left(1-p_{\mathrm{L}}\right)$. Keeping the product constant, but varying $p_{\mathrm{L}}$, it is possible to obtain a good fit between the calculation and experimental results for other values of $d$ and $p_{\mathrm{L}}$. For example, the agreement between the experiment and calculation data (Fig. 9b) was also obtained with the following parameters: $p_{\mathrm{L}}=0, d=6 \mu \mathrm{m}, k_{\mathrm{L}}=0.75 \mathrm{~W} /(\mathrm{m} \cdot \mathrm{K})$, and $h=90 \mathrm{~kW} /\left(\mathrm{m}^{2} \cdot \mathrm{K}\right)$. The layer thermal conductivity $k_{\mathrm{L}}$ of $0.75 \mathrm{~W} /(\mathrm{m} \cdot \mathrm{K})$ is the same as for the case of Fig. 9a. This value was unexpectedly lower than the thermal conductivity of the bulk tokamak graphite, but it was the only one that provided the agreement between the experimental and theoretical results in the cooling curve between two consecutive laser pulses.

To characterize the layer thickness of the backside Tore Supra (Fig. 8a), the layer porosity should be known. If the porosity of the layer and the bulk graphite is the same, the layer thickness should be $8 \mu \mathrm{m}$. For $p_{\mathrm{L}}>$ $25 \%$, the expected layer thickness would be higher than $8 \mu \mathrm{m}$. This layer thickness estimation does not correspond to the measurements of the removed layer thickness $(4 \pm 2 \mu \mathrm{m})$ made with an optical microscope. Only for $p_{\mathrm{L}}<25 \%$, the layer depth is $7 \pm 1 \mu \mathrm{m}$. Thus, $p_{\mathrm{L}}$ close to zero should be accepted in the calculations. The graphite tile manufacturing deteriorates the heat coupling of the porous graphite micro crystals on the tile surface, but does not affect the mean graphite density. It might also reduce the layer thermal conductivity. The mechanical cutting of graphite might cause its pulverization. Then, the graphite pores might be filled with submicrometer graphite dust. Figure 10 presents the scanning electron microscopy (SEM) images of the backside surface of Tore Supra graphite tile. A strong roughness of the graphite surface is observed both before and after LA. Nevertheless, some difference in granularity is noticeable. It is smoother for the surface without the laser pre-treatment (Fig. 10a). This can testify to a higher friability of the surface layer.

\section{CONCLUSION}

The experimental results on LA and LH of the backside non-plasma-facing surface of tokamak graphite tiles 

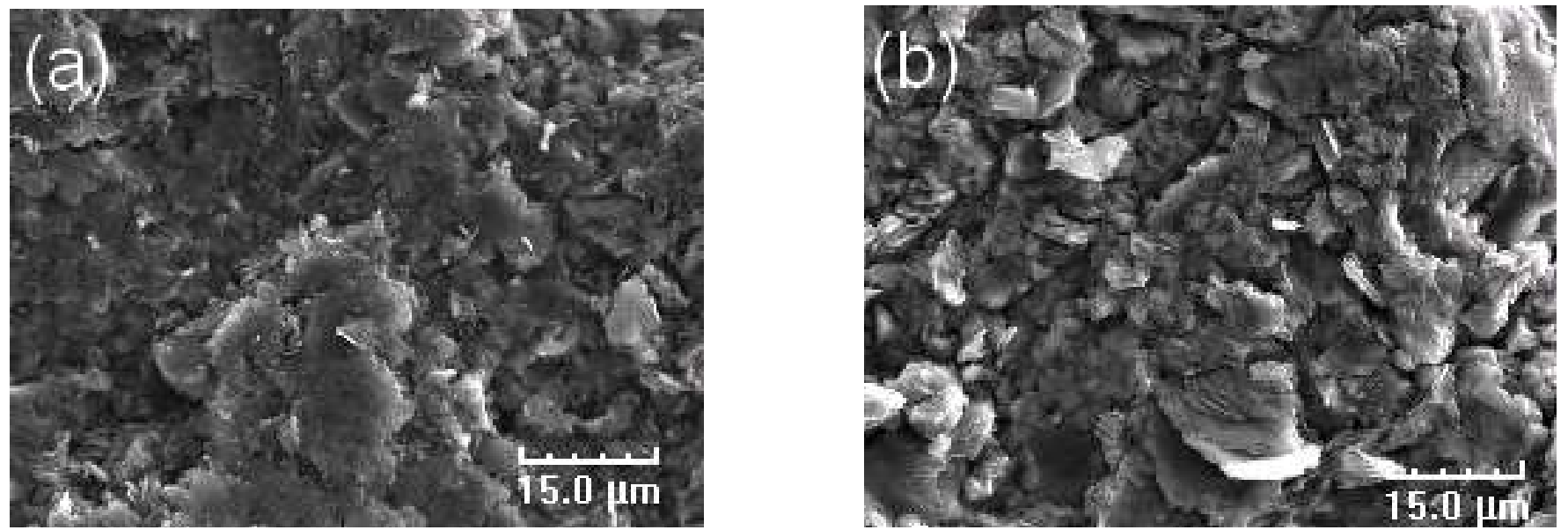

FIG. 10: SEM images of the backside non-plasma-facing surface of Tore Supra graphite tile before (a) and after (b) preprocessing by LA. The measured ablation depth is $4 \pm 2 \mu \mathrm{m}$.

are presented. Two laser benches equipped with the pyrometer system for the temperature measurements were developed for our investigations. For $5 \mathrm{~ns}$ and $100 \mathrm{~ns}$ laser pulses at $\lambda_{\mathrm{L}}=532 \mathrm{~nm}$, the graphite LA thresholds were determined as $1.0 \pm 0.5 \mathrm{~J} / \mathrm{cm}^{2}$ and $2.5 \pm 0.5 \mathrm{~J} / \mathrm{cm}^{2}$, respectively.

The theoretical models of high repetition rate $\mathrm{LH}$ and near-threshold LA of complex surface (substrate with an intermediately adhered layer) were developed to simulate the experimental results and to characterize tokamak graphite. The mean thermal conductivity $k_{\mathrm{G}}=60 \mathrm{~W} /(\mathrm{m} \cdot \mathrm{K})$ of tokamak bulk graphite was obtained by comparing the calculated and experimental results on high repetition rate $(10 \mathrm{kHz}) \mathrm{LH}$ of the graphite surface pre-processed by LA. The experimentally obtained LA thresholds for different pulse durations ( $5 \mathrm{~ns}$ and $100 \mathrm{~ns}$ ) were applied to determine the graphite absorption coefficient. The absorption coefficient of tokamak graphite (averaged over temperature between $T_{0}$ and $\left.T_{\mathrm{S}}\right)$ at $\lambda_{\mathrm{L}}=532 \mathrm{~nm}$ was estimated as $2 \mu \mathrm{m}^{-1}$. This value is unexpectedly low, especially considering the metal-like properties of graphite under normal conditions.

The experimental and calculated LA thresholds and rates of graphite tiles were compared. The good theoretical fit with the experimental results justified the sublimation/evaporation mechanism of nanosecond LA of tokamak graphite.

The high repetition rate $\mathrm{LH}$ measurements on the nonplasma-facing surface of Tore Supra graphite were made with the developed pyrometer system. The temperature traces were significantly different from those expected from thermal and optical properties for tokamak bulk graphite. A hypothesis on a micrometer layer on the surface of manufactured graphite was suggested to explain the obtained results. The layer properties were different from those of tokamak bulk graphite. The layer hypothesis was supported by the LH experiments when the layer was removed by LA from the surface. The experimental temperature trace for the ablated graphite surface corresponded to the theoretical one determined for bulk graphite with the properties specified for tokamak graphite. Thus, the surface layer hypothesis was confirmed by this experiment.

The simulations of the temperature traces obtained by the high repetition rate $\mathrm{LH}$ of the graphite with a surface layer allowed to adjust some unknown layer parameters. The layer parameters (porosity, thickness, thermal conductivity and heat transfer coefficient on the layer/bulk interface) may be determined from the fit of the simulation and experimental results. Thus, the method to characterize the surface layer was developed in our investigations.

The deposited layer LA and LH were also under investigation. A significantly low LA threshold of $0.5 \mathrm{~J} / \mathrm{cm}^{2}$ was obtained for the plasma-facing surface with a thick (several tens of microns) deposited carbon layer (TEXTOR tokamak tile, Garching, Germany). The deposited layer LA threshold was the same for $5 \mathrm{~ns}$ and $100 \mathrm{~ns}$ pulses. A 5-fold difference in the $100 \mathrm{~ns}$ LA thresholds for the deposited layer and graphite may provide LA cleaning of the contaminated surface with deposited carbon layer without graphite substrate damage. The discussion on the results on the deposited layer LA and LH is beyond the scope of this paper and will be presented somewhere else.

\section{ACKNOWLEDGMENTS}

The authors are grateful to Mrs. Cécile Blanc for SEM measurements and to Mr. Miguel Do Nascimento for assistance in refinement of the LA data. This work was performed within the frames of the Euratom - CEA underlying technological program, task UT-S\&E-LASER/DEC. 


\section{APPENDIX A: 3D LASER HEATING MODEL OF THE SURFACES WITH A LAYER}

We suppose the normal incidence of the laser beam on the surface along the $z$-axis. The heat equations for LH of the surface with a layer for temperature distribution $T(t, \mathbf{r})$ are the following:

$$
\begin{aligned}
c_{\mathrm{L}} \frac{\partial T}{\partial t} & =\operatorname{div}\left(k_{\mathrm{L}} \nabla T\right)+Q_{\mathrm{L}}(t, \mathbf{r}) \quad(0<z<d), \\
c_{\mathrm{S}} \frac{\partial T}{\partial t} & =\operatorname{div}\left(k_{\mathrm{S}} \nabla T\right)+Q_{\mathrm{S}}(t, \mathbf{r}) \quad(z>d),
\end{aligned}
$$

where $d$ is layer thickness, $c_{\mathrm{L}}(T)$ and $c_{\mathrm{S}}(T)$ are volume specific heats and $k_{\mathrm{L}}(T)$ and $k_{\mathrm{S}}(T)$ are coefficients of thermal conductivity of the layer and the substrate, respectively, and $Q_{\mathrm{L}}(t, \mathbf{r})$ and $Q_{\mathrm{S}}(t, \mathbf{r})$ are $\mathrm{LH}$ source terms due to absorption of the laser radiation in the layer and, if occurs, in the substrate. The boundary condition should reflect the continuity of the thermal energy flux through the layer/substrate interface $z=d$ :

$$
-\left.k_{\mathrm{L}} \frac{\partial T}{\partial z}\right|_{d-0}=-\left.k_{\mathrm{S}} \frac{\partial T}{\partial z}\right|_{d+0} \equiv q_{\mathrm{d}} .
$$

Extra boundary condition relating the temperature jump and the heat flux on the interface $z=d$ is introduced phenomenologically, with the positive heat transfer coefficient $h$ :

$$
\left.\Delta T_{\mathrm{d}} \equiv T\right|_{z=d-0}-\left.T\right|_{z=d+0}=q_{\mathrm{d}} / h .
$$

Eq. (A4) reflects the thermal resistance of the contact between the layer and the substrate. In two limiting cases of $h \rightarrow 0$ and $h \rightarrow \infty$ we obtain either a completely imperfect or completely perfect heat contact, respectively. With nanosecond $\mathrm{LH}$, the convective and radiation losses on external boundary $z=0$ can be neglected. Thus, the condition $\partial T /\left.\partial z\right|_{z=0}=0$ was used. The initial condition in Eqs. (A1) - (A2) is taken as $\left.T\right|_{t=0}=T_{0}$, where $t=0$ is the time of $\mathrm{LH}$ onset.

The LH source terms $Q_{\mathrm{L}}(t, \mathbf{r})$ and $Q_{\mathrm{S}}(t, \mathbf{r})$ can be deduced from macroscopic electrodynamics. ${ }^{38}$ They are proportional to laser intensity space-time distribution $I\left(t, \mathbf{r}_{\perp}\right)$. Here, $\mathbf{r}_{\perp}$ means either Cartesian coordinates $x$ and $y$ in the plane $z=0$ or polar coordinates $r$ and $\varphi$. The Cartesian coordinates are preferable for the moving laser beam scanning the surface. Function $I\left(t, \mathbf{r}_{\perp}\right)$ can be presented in a factorized form as $I\left(t, \mathbf{r}_{\perp}\right)=I_{0} f_{X Y}(x-v t, y) f_{T}(t)$, where $I_{0}$ is either the steady-state or the peak laser intensity (for continuous or pulsed lasers, respectively), $v$ is laser scanning velocity along the $x$-axis, and the dependences on $\mathbf{r}_{\perp}$ and on $t$ are separated with $f_{X Y}(x, y)$ and $f_{T}(t)$ functions normalized to unity in the maximum. Consequently, the LH source terms are also separated:

$$
\begin{aligned}
& Q_{\mathrm{L}}(t, \mathbf{r})=f_{Z}^{\mathrm{L}}(z) f_{X Y}(x-v t, y) f_{T}(t), \\
& Q_{\mathrm{S}}(t, \mathbf{r})=f_{Z}^{\mathrm{S}}(z) f_{X Y}(x-v t, y) f_{T}(t),
\end{aligned}
$$

with

$$
\begin{aligned}
& f_{Z}^{\mathrm{L}}(z)=I_{0} \frac{\omega \varepsilon_{\mathrm{L}}^{\prime \prime}}{4 c}|\widetilde{C}|^{2}\left|1+\sqrt{\varepsilon_{\mathrm{S}} / \varepsilon_{\mathrm{L}}}\right|^{2} \mathrm{e}^{-\alpha_{\mathrm{L}} d} \\
& \times\left|\mathrm{e}^{\mathrm{i} \omega \sqrt{\varepsilon_{\mathrm{L}}}(z-d) / c}+\frac{1-\sqrt{\varepsilon_{\mathrm{S}} / \varepsilon_{\mathrm{L}}}}{1+\sqrt{\varepsilon_{\mathrm{S}} / \varepsilon_{\mathrm{L}}}} \mathrm{e}^{\mathrm{i} \omega \sqrt{\varepsilon_{\mathrm{L}}}(d-z) / c}\right|^{2} \\
& f_{Z}^{\mathrm{S}}(z)=I_{0} \frac{\omega \varepsilon_{\mathrm{S}}^{\prime \prime}}{c}|\widetilde{C}|^{2} \mathrm{e}^{\alpha_{\mathrm{S}}(d-z)-\alpha_{\mathrm{L}} d}, \\
& \widetilde{C}=4\left\{\left(1+\sqrt{\varepsilon_{\mathrm{L}}}\right)\left(1+\sqrt{\varepsilon_{\mathrm{S}} / \varepsilon_{\mathrm{L}}}\right) \mathrm{e}^{-\mathrm{i} \omega d n_{\mathrm{L}} / c}\right. \\
& \left.\quad+\left(1-\sqrt{\varepsilon_{\mathrm{L}}}\right)\left(1-\sqrt{\varepsilon_{\mathrm{S}} / \varepsilon_{\mathrm{L}}}\right) \mathrm{e}^{\mathrm{i} \omega d n_{\mathrm{L}} / c-\alpha_{\mathrm{L}} d}\right\}^{-1} .
\end{aligned}
$$

Here, $c$ is the light velocity, $\omega$ is the laser frequency, $\varepsilon_{\mathrm{L}}$ and $\varepsilon_{\mathrm{S}}$ are the complex dielectric permittivities of the layer and the substrate, respectively, $\varepsilon_{\mathrm{L}}^{\prime \prime}$ and $\varepsilon_{\mathrm{S}}^{\prime \prime}$ are their imaginary parts related with respective absorption coefficients by $\alpha_{\mathrm{L}}=\omega \varepsilon_{\mathrm{L}}^{\prime \prime} / c n_{\mathrm{L}}$ and $\alpha_{\mathrm{S}}=\omega \varepsilon_{\mathrm{S}}^{\prime \prime} / c n_{\mathrm{S}}$, with $n_{\mathrm{L}}=\operatorname{Re}\left(\sqrt{\varepsilon_{\mathrm{L}}}\right)$ and $n_{\mathrm{S}}=\operatorname{Re}\left(\sqrt{\varepsilon_{\mathrm{S}}}\right)$ the refraction coefficients of the laser light in the boundary layer and in the substrate. The light reflection coefficients $\left(R_{\mathrm{L}}\right.$ and $\left.R_{\mathrm{S}}\right)$ on the interfaces between the corresponding medium and ambient air are expressed through the respective dielectric permittivity. ${ }^{38}$ If the layer thickness $d$ is higher than the laser wavelength, we can average the source term $Q_{\mathrm{L}}(t, \mathbf{r})$ over the laser field spatial oscillations. The averaged source term $\overline{Q_{\mathrm{L}}(t, \mathbf{r})}$ can be expressed as:

$$
\begin{aligned}
& f_{Z}^{\mathrm{L}}(z) \rightarrow \overline{f_{Z}^{\mathrm{L}}(z)}=I_{0} \frac{\omega \varepsilon_{\mathrm{L}}^{\prime \prime}}{4 c}|\widetilde{C}|^{2}\left|1+\sqrt{\varepsilon_{\mathrm{S}} / \varepsilon_{\mathrm{L}}}\right|^{2} \\
& \times\left\{e^{-\alpha_{\mathrm{L}} z}+\left|\frac{1-\sqrt{\varepsilon_{\mathrm{S}} / \varepsilon_{\mathrm{L}}}}{1+\sqrt{\varepsilon_{\mathrm{S}} / \varepsilon_{\mathrm{L}}}}\right|^{2} e^{\alpha_{\mathrm{L}}(z-2 d)}\right\} .
\end{aligned}
$$

As thermal and optical parameters depend on temperature, the direct numerical solution of Eqs. (A1) - (A2) in 3D-space and time for high repetition rate $\mathrm{LH}$ becomes a baffling problem even for moderate computers. It was verified and proved that, for graphite, the exact and the approximate analytical solutions are the same within the pyrometer temperature measurements accuracy. This analytical solution with the constant (mean) matter parameters was used. The final result for the heating temperature $\Delta T(t, \mathbf{r}) \equiv T(t, \mathbf{r})-T_{0}$ in the Cartesian coordinates was obtained by the Fourier method. ${ }^{39}$ It can be presented as:

$$
\begin{aligned}
& \Delta T(t, \mathbf{r})=\iint_{-\infty}^{+\infty} \frac{d \lambda_{x} d \lambda_{y}}{(2 \pi)^{2}} \Phi\left(\lambda_{x}, \lambda_{y}\right) e^{\mathrm{i}\left(x \lambda_{x}+y \lambda_{y}\right)} \\
& \times\left\{\int_{0}^{+\infty} \frac{2 d \lambda_{z}}{\pi} \Theta\left(\lambda_{x}, \lambda_{y}, \lambda_{z}, t\right) \Psi\left(\lambda_{r}, \lambda_{z}\right) Z_{\lambda_{z}}(z)\right. \\
& \left.+\sum_{n=1}^{N\left(\lambda_{r}\right)} \Theta_{n}\left(\lambda_{x}, \lambda_{y}, t\right) \Psi_{n}\left(\lambda_{r}\right) Z_{\chi_{n}}(z)\right\}
\end{aligned}
$$


where $\lambda_{r}=\sqrt{\lambda_{x}^{2}+\lambda_{y}^{2}}$, and $Z_{\lambda_{z}}(z)$ and $Z_{\chi_{n}}(z)$ are eigenfunctions of relevant boundary problem for continuous and discrete spectrum of eigenvalues $\lambda_{z}$ and $\chi_{n}$, respectively. In Eq. (A8), the different functions are defined as:

$$
\begin{gathered}
\Phi\left(\lambda_{x}, \lambda_{y}\right)=\iint_{-\infty}^{+\infty} e^{-\mathrm{i}\left(x \lambda_{x}+y \lambda_{y}\right)} f_{X Y}(x, y) d x d y \\
\Theta\left(\lambda_{x}, \lambda_{y}, \lambda_{z}, t\right)=\int_{0}^{t} e^{-i v \lambda_{x} t^{\prime}} f_{T}\left(t^{\prime}\right) e^{D_{\mathrm{S}}\left(\lambda_{r}^{2}+\lambda_{z}^{2}\right)\left(t^{\prime}-t\right)} d t^{\prime}, \\
\Theta_{n}\left(\lambda_{x}, \lambda_{y}, t\right)=\int_{0}^{t} e^{-i v \lambda_{x} t^{\prime}} f_{T}\left(t^{\prime}\right) e^{D_{\mathrm{S}}\left(\lambda_{r}^{2}-\chi_{n}^{2}\right)\left(t^{\prime}-t\right)} d t^{\prime}, \\
\Psi\left(\lambda_{r}, \lambda_{z}\right)=\frac{1}{c_{\mathrm{S}}} \int_{0}^{+\infty} d z f_{Z}(z) Z_{\lambda_{z}}(z), \\
\Psi_{n}\left(\lambda_{r}\right)=\frac{1}{c_{\mathrm{S}}} \int_{0}^{+\infty} d z f_{Z}(z) Z_{\chi_{n}}(z) .
\end{gathered}
$$

Here and after, $D_{\mathrm{L}}=k_{\mathrm{L}} / c_{\mathrm{L}}$ and $D_{\mathrm{S}}=k_{\mathrm{S}} / c_{\mathrm{S}}$ are the thermal diffusivity coefficients of the layer and the substrate, respectively, and $f_{Z}(z)=\overline{f_{Z}^{\mathrm{L}}(z)}$ at $0<z<d$ and $f_{Z}(z)=f_{Z}^{\mathrm{S}}(z)$ at $z>d$. The above integrals might be expressed analytically. Function $\Phi\left(\lambda_{x}, \lambda_{y}\right)$ is defined by the spatial distribution of the laser intensity. It may be simplified for the Gaussian and homogeneous intensity distributions. In the latter case $\Phi\left(\lambda_{x}, \lambda_{y}\right)=2 \pi r_{0} J_{1}\left(r_{0} \lambda_{r}\right) / \lambda_{r}$, where $r_{0}$ is the radius of a circular laser spot and $J_{1}(x)$ is the Bessel function.

Functions $\Theta\left(\lambda_{x}, \lambda_{y}, \lambda_{z}, t\right)$ and $\Theta_{n}\left(\lambda_{x}, \lambda_{y}, t\right)$ are defined by the time dependence of the laser intensity. They may be simplified both for continuous and pulsed lasers with rectangular pulses or $\sin ^{2}$-pulses. For rectangular pulses with duration $\tau_{\mathrm{p}}$ and repetition rate $\nu_{\mathrm{L}}\left(f_{T}(t)=1\right.$ at $m / \nu_{\mathrm{L}}<t<\tau_{\mathrm{p}}+m / \nu_{\mathrm{L}}, m=0,1,2, \ldots$, otherwise $f_{T}(t)=0$ ), the continuous spectrum $\Theta$-function is expressed as:

$$
\begin{aligned}
& \Theta\left(\lambda_{x}, \lambda_{y}, \lambda_{z}, t\right)=\exp \left(-\mathrm{i} \lambda_{x} v t\right) \\
& \times\left\{\begin{array}{l}
\frac{\left(e^{\Lambda_{z} m / \nu_{\mathrm{L}}}-1\right)\left(e^{\Lambda_{z} \tau_{\mathrm{p}}}-1\right) e^{-\Lambda_{z} t}}{\left(e^{\Lambda_{z} / \nu_{\mathrm{L}}}-1\right) \Lambda_{z}}+\frac{1-e^{\Lambda_{z}\left(m / \nu_{\mathrm{L}}-t\right)}}{\Lambda_{z}}, \\
\frac{\left(e^{\Lambda_{z}(m+1) / \nu_{\mathrm{L}}}-1\right)\left(e^{\Lambda_{z} \tau_{\mathrm{p}}}-1\right) e^{-\Lambda_{z} t}}{\left(e^{\Lambda_{z} / \nu_{\mathrm{L}}}-1\right) \Lambda_{z}},
\end{array}\right.
\end{aligned}
$$

where $\Lambda_{z}=D_{\mathrm{S}}\left(\lambda_{r}^{2}+\lambda_{z}^{2}\right)-\mathrm{i} v \lambda_{x}$, upper line corresponds to $m / \nu_{\mathrm{L}}<t<m / \nu_{\mathrm{L}}+\tau_{p}$ (during the pulses) and lower line corresponds to $m / \nu_{\mathrm{L}}+\tau_{\mathrm{p}}<t<(m+1) / \nu_{\mathrm{L}}$ (between the pulses). The function $\Theta_{n}\left(\lambda_{x}, \lambda_{y}, t\right)$ can be obtained by substitution $\Lambda_{z} \rightarrow \Lambda_{n}=D_{\mathrm{S}}\left(\lambda_{r}^{2}-\chi_{n}^{2}\right)-\mathrm{i} v \lambda_{x}$.

To express explicitly functions $\Psi\left(\lambda_{r}, \lambda_{z}\right)$ and $\Psi_{n}\left(\lambda_{r}\right)$ defined by the $z$-dependence of the LH source terms, one should know eigenfunctions of the boundary problem, $Z_{\lambda_{z}}(z)$ and $Z_{\chi_{n}}(z)$. For arbitrary eigenvalue $\lambda_{z}$, eigenfunction $Z_{\lambda_{z}}(z)$ satisfies the equations:

$$
\begin{aligned}
& Z_{\lambda_{z}}^{\prime \prime}=-\left[\left(\lambda_{r}^{2}+\lambda_{z}^{2}\right) D_{\mathrm{S}} / D_{\mathrm{L}}-\lambda_{r}^{2}\right] Z_{\lambda_{z}} \quad(0<z<d), \\
& Z_{\lambda_{z}}^{\prime \prime}=-\lambda_{z}^{2} Z_{\lambda_{z}} \quad(z>d)
\end{aligned}
$$

with the boundary conditions $\left.Z_{\lambda_{z}}\right|_{d-0}-\left.Z_{\lambda_{z}}\right|_{d+0}=$ $-\left.\left(k_{\mathrm{L}} / h\right) Z_{\lambda_{z}}^{\prime}\right|_{d-0},\left.k_{\mathrm{L}} Z_{\lambda_{z}}^{\prime}\right|_{d-0}=\left.k_{\mathrm{S}} Z_{\lambda_{z}}^{\prime}\right|_{d+0},\left.Z_{\lambda_{z}}^{\prime}\right|_{z=0}=$ 0 . For the heating of the surface with a layer, the eigenvalue spectrum contains both the continuous and discrete parts. The continuous spectrum corresponds to real values of $\lambda_{z}$. In this case, the solution of Eqs. (A9) - (A10) is:

$$
\begin{aligned}
& Z_{\lambda_{z}}(z)=\frac{\cos (\lambda z)}{\sqrt{A^{2}+B^{2}}} \quad(0<z<d), \\
& Z_{\lambda_{z}}(z>d)=\frac{A \sin \left(\lambda_{z} z\right)+B \cos \left(\lambda_{z} z\right)}{\sqrt{A^{2}+B^{2}}},
\end{aligned}
$$

where $\lambda=\sqrt{\left(\lambda_{r}^{2}+\lambda_{z}^{2}\right) D_{\mathrm{S}} / D_{\mathrm{L}}-\lambda_{r}^{2}}$, and

$$
\begin{aligned}
& A=p \sin \left(\lambda_{z} d\right)-\frac{k_{\mathrm{L}} \lambda}{k_{\mathrm{S}} \lambda_{z}} \cos \left(\lambda_{z} d\right) \sin (\lambda d), \\
& B=p \cos \left(\lambda_{z} d\right)+\frac{k_{\mathrm{L}} \lambda}{k_{\mathrm{S}} \lambda_{z}} \sin \left(\lambda_{z} d\right) \sin (\lambda d),
\end{aligned}
$$

with $p=\cos (\lambda d)-\left(k_{\mathrm{L}} \lambda / h\right) \sin (\lambda d)$. For the discrete set of eigenvalues, with pure imaginary values of $\lambda_{z}=i \chi$ $(\chi>0)$, the set of eigenvalues will be defined as $\chi_{n}$ with $n=1,2, \ldots$ Then, eigenfunctions $Z_{\chi_{n}}(z)$ of the discrete spectrum have the form:

$$
\begin{aligned}
& Z_{\chi_{n}}(z)=a_{n} \cos \left(\lambda_{n} z\right) \quad(0<z<d), \\
& Z_{\chi_{n}}(z>d)=a_{n}\left(\cos \left(\lambda_{n} d\right)-\frac{k_{\mathrm{L}} \lambda_{n}}{h} \sin \left(\lambda_{n} d\right)\right) e^{-\chi_{n}(z-d)},
\end{aligned}
$$

where $\lambda_{n}=\sqrt{\left(\lambda_{r}^{2}-\chi_{n}^{2}\right) D_{\mathrm{S}} / D_{\mathrm{L}}-\lambda_{r}^{2}}, a_{n}$ is the normalization constant, and the $\chi_{n}$-value should satisfy the equation:

$$
\lambda_{n} \tan \left(\lambda_{n} d\right)=\frac{h k_{\mathrm{S}} \chi_{n}}{k_{\mathrm{L}}\left(h+k_{\mathrm{S}} \chi_{n}\right)} .
$$

For $D_{\mathrm{S}} / D_{\mathrm{L}} \leq 1$, Eq. (A11) for each value of $\lambda_{r}$ has no solutions. Thus, the discrete spectrum does not exist. For $D_{\mathrm{S}} / D_{\mathrm{L}}>1$, the discrete spectrum is always present (except for the 1D model, where $\lambda_{r}=0$ ). For each nonzero $\lambda_{r}$ the solutions belong to $0<\chi_{n}<\lambda_{r} \sqrt{1-D_{\mathrm{L}} / D_{\mathrm{S}}}$, when $\lambda_{n}$ is real, and the number of solutions increases with increasing $\lambda_{r}$. If $N\left(\lambda_{r}\right) \geq 1$ defines the total finite number of solutions of Eq. (A11) for the given $\lambda_{r}, \chi_{n}\left(\lambda_{r}\right)$ defines the discrete eigenvalue for $1 \leq n \leq N\left(\lambda_{r}\right)$.

By integrating over $z$, the expressions for functions $\Psi\left(\lambda_{r}, \lambda_{z}\right)$ and $\Psi_{n}\left(\lambda_{r}\right)$ are obtained:

$$
\begin{aligned}
& \Psi\left(\lambda_{r}, \lambda_{z}\right)=\frac{\left(\tilde{a}^{(+)}-\tilde{a}^{(-)} e^{-2 d \alpha_{\mathrm{L}}}\right) \alpha_{\mathrm{L}}}{c_{\mathrm{S}}\left(\lambda^{2}+\alpha_{\mathrm{L}}^{2}\right) \sqrt{A^{2}+B^{2}}} \\
& +\frac{\left(\tilde{a}^{(+)}+\tilde{a}^{(-)}\right) \lambda \sin (\lambda d)-\left(\tilde{a}^{(+)}-\tilde{a}^{(-)}\right) \alpha_{\mathrm{L}} \cos (\lambda d)}{e^{d \alpha_{\mathrm{L}}} c_{\mathrm{S}}\left(\lambda^{2}+\alpha_{\mathrm{L}}^{2}\right) \sqrt{A^{2}+B^{2}}} \\
& +\frac{\tilde{b}\left\{\left(A \alpha_{\mathrm{S}}-B \lambda_{z}\right) \sin \left(\lambda_{z} d\right)+\left(B \alpha_{\mathrm{S}}+A \lambda_{z}\right) \cos \left(\lambda_{z} d\right)\right\}}{e^{d \alpha_{\mathrm{L}}} c_{\mathrm{S}}\left(\lambda_{z}^{2}+\alpha_{\mathrm{S}}^{2}\right) \sqrt{A^{2}+B^{2}}},
\end{aligned}
$$




$$
\begin{aligned}
& \Psi_{n}\left(\lambda_{r}\right)=\frac{a_{n}\left(\tilde{a}^{(+)}-\tilde{a}^{(-)} e^{-2 d \alpha_{\mathrm{L}}}\right) \alpha_{\mathrm{L}}}{c_{\mathrm{S}}\left(\lambda_{n}^{2}+\alpha_{\mathrm{L}}^{2}\right)} \\
& +\frac{\left(\tilde{a}^{(+)}+\tilde{a}^{(-)}\right) \lambda_{n} \sin \left(\lambda_{n} d\right)-\left(\tilde{a}^{(+)}-\tilde{a}^{(-)}\right) \alpha_{\mathrm{L}} \cos \left(\lambda_{n} d\right)}{e^{d \alpha_{\mathrm{L}}} c_{\mathrm{S}}\left(\lambda_{n}^{2}+\alpha_{\mathrm{L}}^{2}\right) a_{n}^{-1}} \\
& +\frac{\tilde{b}\left\{\cos \left(\lambda_{n} d\right)-\left(k_{\mathrm{L}} \lambda_{n} / h\right) \sin \left(\lambda_{n} d\right)\right\}}{e^{d \alpha_{\mathrm{L}}} c_{\mathrm{S}}\left(\chi_{n}+\alpha_{\mathrm{S}}\right) a_{n}^{-1}}
\end{aligned}
$$

where $\tilde{a}^{( \pm)}=I_{0} \frac{\omega \varepsilon_{\mathrm{L}}^{\prime \prime}}{4 c}|\widetilde{C}|^{2}\left|1 \pm \sqrt{\varepsilon_{\mathrm{S}} / \varepsilon_{\mathrm{L}}}\right|^{2}, \tilde{b}=I_{0} \frac{\omega \varepsilon_{\mathrm{S}}^{\prime \prime}}{c}|\widetilde{C}|^{2}$.

These expressions present the analytical solution of the LH of the surface with a boundary layer and with intermediate heat contact between the layer and the substrate, in the rectangular geometry for the general case of scanning pulsed laser beam. The simplified version of this solution can be obtained in the cylindrical geometry with circular symmetry of the laser spot and immobile laser beam. In this case, the heating temperature is expressed by:

$$
\begin{aligned}
& \Delta T(t, r, z)=\int_{0}^{+\infty} d \lambda_{r} \Phi\left(\lambda_{r}\right) J_{0}\left(r \lambda_{r}\right) \\
& \times\left\{\int_{0}^{+\infty} \frac{2 d \lambda_{z}}{\pi} \Theta\left(\lambda_{r}, \lambda_{z}, t\right) \Psi\left(\lambda_{r}, \lambda_{z}\right) Z_{\lambda_{z}}(z)\right. \\
& \left.+\sum_{n=1}^{N\left(\lambda_{r}\right)} \Theta_{n}\left(\lambda_{r}, t\right) \Psi_{n}\left(\lambda_{r}\right) Z_{\chi_{n}}(z)\right\}
\end{aligned}
$$

where $v=0$ should be used in the corresponding expressions for $\Theta$-functions. For homogeneous laser intensity distribution, $\Phi\left(\lambda_{r}\right)=r_{0} J_{1}\left(r_{0} \lambda_{r}\right)$ should be applied.

\section{APPENDIX B: 1D LASER ABLATION MODEL OF SUBLIMATING MATERIALS}

One-dimensional approximation is applied to consider LA on nanosecond time scale (for a single laser pulse) with the spot diameter of $\sim 1 \mathrm{~mm}$. Surface pre-heating by previous laser pulses can be taken into account by the initial condition $T(t=0, z)=T_{0}+\Delta T_{n}^{*}(z)$, where $T_{0}$ is the ambient temperature and $\Delta T_{n}^{*}(z)$ is the surface heating temperature just before the $n$-th laser pulse application. Saturation of the surface pre-heating temperature results from the finite size of the laser spot: $\Delta T_{n}^{*}(z=0) \rightarrow \Delta T^{*}$ at $n \rightarrow+\infty$. The calculations of $\Delta T_{n}^{*}(z)$ are made with the $3 \mathrm{D}$ LH model (Appendix A).

If the laser fluence $F$ is less than the ablation threshold $F_{\mathrm{th}}$, the temperature field $T(t, z)$ can be described by the one-dimensional version of Eqs. (A1) - (A2). For the laser fluence $F$ above the ablation threshold $F_{\mathrm{th}}$, the surface temperature should be higher than the sublimation temperature $T_{\mathrm{S}}$, if LA is not taken into account. For $F>F_{\mathrm{th}}$, three intervals for the laser beam interaction with the surface may be distinguished.

For $0<t<t_{1}$ with $t_{1}<\tau_{\mathrm{p}}$, the surface temperature increases in time up to sublimation temperature, so $T(t, z=0)<T_{\mathrm{S}}$, with $T\left(t_{1}, z=0\right)=T_{\mathrm{S}}$. During LA stage $t_{1} \leq t \leq t_{2}$, the surface temperature should be set equal to the sublimation temperature $T_{\mathrm{S}}\left(t_{2}\right.$ can differ from $\tau_{\mathrm{p}}$, depending on the laser pulse shape and difference $\left.F-F_{\mathrm{th}}\right)$. In accordance with the energy conservation law, ${ }^{32,37}$ the Stefan boundary condition on the moving external boundary of the surface is applied:

$$
\left.k_{\mathrm{L}}\left(T_{\mathrm{S}}\right) \frac{\partial T}{\partial z}\right|_{z=z_{\mathrm{A}}(t)}=L \rho_{\mathrm{L}} v_{\mathrm{A}}(t)
$$

Here, $L$ is the mass specific heat of sublimation, $\rho_{\mathrm{L}}$ is the matter density, and $v_{\mathrm{A}}(t)=d z_{\mathrm{A}}(t) / d t$ is the speed of LA front. For $t>t_{2}$, the surface temperature is lower than the sublimation temperature, $T(t, z=0)<T_{\mathrm{S}}$, and the surface is not ablated. The LA depth $H$ for the $n$-th laser pulse can be calculated through the self-consistently found speed of LA front as: $H=\int_{t_{1}}^{t_{2}} v_{\mathrm{A}}(t) d t \equiv z_{\mathrm{A}}\left(t_{2}\right)$.
1 I. Youle and A.A. Haasz, J. Nucl. Mater. 248, 64 (1997).

2 G. Federici, R.A. Anderl, P. Andrew, J.N. Brooks, R.A. Causey, J.P. Coad, D. Cowgill, R.P. Doerner, A.A. Haasz, G. Janeschitz, W. Jacob, G.R. Longhurst, R. Nygren, A. Peacock, M.A. Pick, V. Philipps, J. Roth, C.H. Skinner, and W.R. Wampler, J. Nucl. Mater. 266-269, 14 (1999).

${ }^{3}$ P. Andrew, D. Brennan, J.P. Coad, J. Ehrenberg, M. Gadeberg, A. Gibson, M. Groth, J. How, O.N. Jarvis, H. Jensen, R. Lässer, F. Marcus, R. Monk, P. Morgan, J. Orchard, A. Peacock, R. Pearce, M. Pick, A. Rossi, B. Schunke, M. Stamp, M. von Hellermann, D.L. Hillis, and J. Hogan, J. Nucl. Mater. 266-269, 153 (1999).

${ }^{4}$ M. Friedrich, W. Pilz, G. Sun, R. Behrisch, C. GarciaRosales, N. Bekris, and R.-D. Penzhon, Nucl. Instrum. and Meth. B 161-163, 216 (2000).

${ }^{5}$ R.A. Causey, J. Nucl. Mater. 300, 91 (2002).

${ }^{6}$ T. Tanabe, N. Bekris, P. Coad, C.H. Skinner, M. Glugda, and N. Miya, J. Nucl. Mater. 313-316, 478 (2003).
7 C.H. Skinner, J.P. Coad, and G. Federici, Physica Scripta T111, 92 (2004).

${ }^{8}$ C.H. Skinner, H. Kugel, D. Mueller, B.L. Doyle, and W.R. Wampler, Tritium Removal by $\mathrm{CO}_{2}$ Laser Heating, Proceedings of the $17^{\text {th }}$ IEEE/NPSS Symposium on Fusion Engeneering (SOFE'97, 6-9 October 1997, San Diego, USA), vol.1, 321-324 (1998).

9 C.H. Skinner, C.A. Gentile, A. Carpe, G. Guttadora, S. Langish, K.M. Young, W.M. Shu, and H. Nakamura, J. Nucl. Mater. 301, 98 (2002).

10 C.H. Skinner, N. Bekris, J.P. Coad, C.A. Gentile, and M. Glugda, J. Nucl. Mater. 313-316, 496 (2003).

11 K.J. Gibson, G.F. Counsell, C. Curran, M.J. Forrest, M.J. Kay, and K.J. Watkins, J. Nucl. Mater. 337-339, 565 (2005).

12 B. Emmoth, S. Khartsev, A. Pisarev, A. Grishin, U. Karlsson, A. Litnovsky, M. Rubel, and P. Wienhold, J. Nucl. Mater. 337-339, 639 (2005). 
13 W. Shu, Y. Kawakubo, G.N. Luo, and M. Nishi, J. Nucl. Sci. Tech. 40, 1019 (2003).

14 W.M. Shu, Y. Kawakubo, K. Masaki, and M.F. Nishi, J. Nucl. Mater. 313-316, 584 (2003).

15 F. Le Guern, C. Hubert, S. Mousset, E. Gautier, C. Blanc, P. Wodling, and J.M. Weulersse, J. Nucl. Mater. 335, 410 (2004).

16 T. Shibahara, Y. Sakawa, and T. Tanabe, J. Nucl. Mater. 337-339, 654 (2005).

17 Y. Sakawa, T. Shibahara, K. Sato, and T. Tanabe, J. Plasma Fusion Res. Series 7, 138 (2006).

18 Y. Sakawa, K. Sato, T. Shibahara, and T. Tanabe, Fusion. Eng. Des. 81, 381 (2006).

19 B. Schweer, A. Huber, G. Sergienko, V. Philipps, F. Irrek, H.G. Esser, V. Samm, M. Kempenaar, M. Stamp, C. Gowers, and D. Richards, J. Nucl. Mater. 337-339, 570 (2005).

20 Ch.L. Mantell, Carbon and Graphite Handbook (Interscience Publishers, New York, 1968).

21 Physical Quantities Handbook, edited by I.S. Grigoryev and E.S. Meilikhov (Energoatomizdat, Moscow, 1991) (in Russian).

22 A. Semerok, J.-M. Weulersse, F. Brygo, Ch. Lascoutouna, Ch. Hubert, F. Le Guern, and M. Tabarant, Studies on graphite surfaces detritiation by pulsed repetition rate nanosecond lasers, CEA report NT DPC/SCP/04-076-A (2004) (unpublished).

23 A. Semerok, J.-M. Weulersse, F. Brygo, D. Farcage, C. Hubert, C. Lascoutouna, M. Géléoc, P. Wodling, H. Long, F. Champonnois, G. Brunel, G. Vimond, E. Lizon, V. Dauvois, V. Delanne, C. Grisolia, S. Fomichev, and M. Hashida, Studies on tokamak wall surfaces decontamination by pulsed repetition rate lasers, CEA report NT DPC/SCP/05-111-A (2005) (unpublished).

24 A. Semerok, F. Brygo, S.V. Fomichev, F. Champonnois, J.-M. Weulersse, P.-Y. Thro, P. Fichet, and C. Grisolia, Laser detritiation and co-deposited layer characterisation for future ITER installation, The 9th European Nuclear Conference Book of abstracts, Numéro Spécial ENC 2005, Revue Générale Nucléaire, no.6, p. 66 (2005); ENC 2005 Proceedings on CD-ROM, Full length papers - Session 11 (Versailles, France, 2005).

25 Industrial Carbon and Graphite, Papers read at the Conference held in London $24^{\text {th }}-26^{\text {th }}$ September 1957, pp.37-41 (Society of Chemical Industry, London, 1958).
${ }^{26}$ M. Lipa, Ph. Chappuis, G. Chaumat, D. Guilhem, R. Mitteau, and L. Plöchl, Development and fabrication of improved CFC-brazed components for the inner first wall of Tore Supra, Fusion Technology 96 (Proceedings of the $19^{\text {th }}$ Simposium on Fusion Technology (SOFT'96), 16-20 September 1996, Lisbon, Portugal, edited by C. Varandas and F. Serra), pp.439-442 (Elsevier Science B.V., 1997).

27 S. Ergun, Optical Studies of Carbon, in: Chemistry and Physics of Carbon, edited by Ph.L. Walker Jr., vol. 3, pp.45-119 (Dekker, New York, 1968).

28 http://www.azom.com (The A to Z of Materials: CarbonGraphite Materials).

${ }^{29}$ C.H. Skiner, N. Bekris, J.P. Coad, C.A. Gentile, A. Hassanrin, R. Reiswig, and S. Willms, Physica Scripta T103, 34 (2003).

30 S.V. Fomichev, A. Semerok, J.-M. Weulersse, and F. Brygo, Modelling of complex surface heating by continuous and pulsed lasers, CEA report NT DPC/SCP/05-109-A, 2005 (unpublished).

31 A. Semerok, S.V. Fomichev, F. Brygo, J.-M. Weulersse, P.-Y. Thro, and C. Grisolia, Surface heating by pulsed repetition rate nanoseconds lasers, Proceedings of "LTL Plovdiv 2005" (IV International Symposium Laser Technologies and Lasers "LTL Plovdiv 2005", Bulgaria, Plovdiv, October 8-10 2005), pp.76-83 (2006).

32 A.M. Prokhorov, V.I. Konov, I. Ursu, and I.N. Mihailescu, Laser Heating of Metals (Adam Hilger, Bristol, 1990).

33 J. Steinbeck, G. Braunstein, M.S. Dresselhaus, T. Venkatesan, and D.C. Jacobson, J. Appl. Phys. 58, 4374 (1985).

34 N.W. Ashcroft and N.D. Mermin, Solid State Physics (Holt Rinehart and Winston, New York, 1976).

${ }^{35}$ H.S. Carslaw and J.C. Jaeger, Conduction of Heat in Solids 2nd edition (Oxford University Press, Oxford, 1959).

36 V.S. Arpaci, Conduction Heat Transfer (Addison-Wesley, Reading, MA, 1966).

37 E.N. Sobol, Phase Transformations and Ablation in LaserTreated Solids (Wiley Interscience Publication, New York, 1995).

38 L.D. Landau, E.M. Lifshitz, and L.P. Pitaevskii, Electrodynamics of Continuous Media 2nd rev. and enl. edition (Butterworth-Heinemann, Oxford, 1995).

39 P.M. Morse and H. Feshbach, Methods of Theoretical Physics (McGraw-Hill, NewYork, 1953). 